\title{
A COVID-19 sob a ótica de professores da educação superior no Brasil
}

\author{
COVID-19 from the perspective of higher education teachers in Brazil
}

\author{
Rosemeire de Araújo Rangni (iD https://orcid.org/0000-0002-8252-9745 \\ Universidade Federal de São Carlos \\ e-mail - rose.rangni@ufscar.br
}

Bárbara Amaral Martins (iD https://orcid.org/0000-0003-4278-1661

Universidade Federal de Mato Grosso do Sul

e-mail-barbara.martins@ufms.br

\section{Resumo}

A COVID-19 desencadeou uma pandemia com consequências sanitárias, sociais e econômicas de grandes proporções. Como estratégias de enfrentamento do problema, países fecharam fronteiras e estabeleceram medidas de distanciamento social de maior ou menor restrição. Nesse contexto, tivemos por objetivo identificar os impactos do distanciamento social em professores da educação superior no Brasil em tempo de pandêmica da COVID-19. A pesquisa desenhou-se como descritiva, com delineamento survey. Os dados foram coletados por meio de questionários online e submetidos à análise lexical, a partir do processamento no software IRAMUTEQ. O presente estudo envolveu 67 docentes de instituições de educação superior públicas e privadas do Brasil. Os resultados revelaram efeitos emocionais prejudiciais e sobrecarga de trabalho, mas alguns professores também demonstraram resiliência ao buscarem tirar o melhor proveito possível da adversidade.

Palavras-chave: Doença epidêmica. Educação superior. Professores de educação superior.

\begin{abstract}
The COVID-19 virus has unleashed a pandemic with devastating health and socioeconomic consequences for the world. As strategies to face the problem, countries closed borders and established social distancing measures, to a greater or lesser extent. In this context, we aimed to identify the impacts of social distancing on higher education professors in Brazil at a time of COVID19 pandemic. The research was characterized as descriptive, with a survey design. The data were collected through online questionnaires and submitted to lexical analysis from processing in IRAMUTEQ software. The present study involved 67 professors from public and private higher education institutions in Brazil. The results revealed harmful emotional effects and work overload, but some professors also demonstrated resilience in trying to get the most out of the adversity.
\end{abstract}

Keywords: Epidemic disease; Higher education; Higher education professors. 


\section{Introdução}

Em dezembro de 2019, descobriu-se a circulação de um vírus na cidade de Wuhan, em Hubei - China, causador de uma infecção respiratória aguda. Após a realização de diversos estudos etiológicos, concluiu-se que se trata de um novo agente viral, o qual integra o grupo dos coronavírus e foi denominado COVID-19. O coronavírus é uma família de vírus que causa infecções respiratórias, descoberto na década de 1960, de acordo com o Ministério da Saúde.

A rapidez com que essa nova enfermidade se espalha fez com que a propagação tomasse proporções globais, de maneira que em março de 2020, a Organização Mundial da Saúde (OMS) declarou a ocorrência de uma pandemia (DÍAZCASTRILLÓN; TORO-MONTOYA, 2020).

Como estratégias de prevenção e enfrentamento da COVID-19, houve fechamento de fronteiras e adoção de medidas como isolamento, distanciamento social, quarentena e contenção comunitária ou bloqueio (lockdown). $\mathrm{O}$ isolamento abrange os casos confirmados da doença e tem a finalidade de separá-los das demais pessoas para reduzir o risco de contágio. A quarentena é destinada às pessoas que, supostamente, foram expostas ao vírus, no entanto, encontram-se sem sintomas, seja porque não foram infectadas, seja porque estão no período de incubação do vírus, ou ainda, porque integram os casos positivos assintomáticos.

A movimentação das pessoas em quarentena torna-se restrita e acontece o monitoramento de eventuais sintomas. Já o distanciamento social é aplicado tanto às pessoas infectadas ou com suspeita quanto às não infectadas, pois consiste na imposição de restrições cuja finalidade é afastar fisicamente os indivíduos para que a propagação seja controlada. Em última instância, a contenção comunitária ou bloqueio proíbe que a população saia das residências (salvo para fins considerados essenciais, como atendimento médico e compra de suprimentos básicos), promovendo uma drástica diminuição no contato social (AQUINO et al., 2020).

A abrangência das ações é estabelecida pelos governos e essa decisão tende a ser influenciada pelo avanço ou controle da propagação do vírus na localidade, de modo que podem ser observadas maiores ou menores restrições. A opção por determinadas medidas também é inspirada pela observação dos resultados obtidos em diferentes países e divulgados pela OMS.

O Brasil, enquanto república federativa, é formado por estados e municípios que possuem certa autonomia no estabelecimento de leis e recomendações referentes à prevenção e enfrentamento da COVID-19. Vale esclarecer que tal autonomia para a adoção de medidas contra a pandemia nos respectivos territórios foi assegurada pelo ministro Alexandre de Moraes, em oposição a "atos omissivos e comissivos do Poder Executivo federal, praticados durante a crise de saúde pública" (SUPREMO TRIBUNAL FEDERAL, 2020, s.p). Dessa maneira, os procedimentos e as restrições efetivadas não são uniformes em território nacional, mas, de uma forma ou outra, impuseram modificações repentinas na rotina da população, visto que a grave crise sanitária que se instalou tem exigido mudanças radicais nos hábitos e nas rotinas das pessoas. Contudo, para além das mudanças na dinâmica cotidiana, são muitos os que perderam entes queridos ou

Revista de Estudos e Pesquisas sobre Ensino Tecnológico, v. 6, Edição Especial Desafios e avanços educacionais em tempos da COVID-19, 140720, 2020. 
que temem não conseguir sobreviver a um possível contágio por comporem o chamado grupo de risco (BOLETIM EPIDEMIOLÓGICO, 2020).

Sendo o distanciamento social, uma maneira reconhecidamente eficiente de conter a disseminação da doença, temos presenciado o fechamento de escolas, universidades, locais de trabalho, comércios, bem como o cancelamento de espetáculos e demais eventos que possam ocasionar aglomerações (AQUINO et al., 2020). As atividades passíveis de serem realizadas à distância passaram a ser desenvolvidas remotamente, outras foram suspensas ou entraram em regime de escalonamento. É nesse cenário de recolhimento e transformações abruptas que a educação formal tem tentado acontecer. Rapidamente, professores de todos os níveis de ensino tiveram que reinventar suas práticas a fim de impulsionar a aprendizagem de crianças, adolescentes, jovens e adultos. Como se isso já não fosse, por si só, algo complexo, o novo formato de processo de ensino e aprendizagem ocorre no Brasil, pois, cerca de $79,9 \%$ da população têm acesso à internet no domicílio, mas apenas $40,2 \%$ dispõem de computador conectado à rede. Entre as pessoas que vivem em situação de pobreza1 ${ }^{1}$, esse percentual não passa de 13,1\% (INSTITUTO BRASILEIRO DE GEOGRAFIA E ESTATÍSTICA [IBGE], 2019).

Em relação às universidades federais e demais instituições de ensino de âmbito federal, inicialmente, a Portaria $343 / 2020$ em seu artigo $1^{\circ}$ autorizou por 30 dias a suspenção das aulas presenciais para a condição remota. Com o prosseguimento de casos, em maio de 2020, a Portaria $n^{\circ} 544$ dispôs sobre a substituição de aulas presenciais para aulas em meios digitais, enquanto perdurar a pandemia.

Dentre todos os educadores que enfrentam os novos desafios impostos pela pandemia, voltamos nosso olhar para os que atuam no âmbito da educação superior, cuja tarefa, não raramente, ultrapassa os limites das atividades de ensino e envolve a produção de conhecimento científico e a extensão universitária. Diante do atual contexto, podemos elencar alguns possíveis desafios: falta de domínio dos recursos tecnológicos que podem ser usados para o desenvolvimento dos conteúdos curriculares; existência de estudantes que não possuam acesso à internet ou recursos materiais (computadores, local e mobiliário para estudo) ou que dispõem unicamente de celular para realizar as atividades propostas; dificuldade em dar continuidade às pesquisas científicas que exigem ida a campo; bem como em realizar atividades de extensão universitária diante do distanciamento da comunidade interna e externa. Além disso, esses profissionais também estão sujeitos aos efeitos psicológicos que podem ser desencadeados pela grave crise de saúde coletiva, inclusive, estar entre a população de risco (SOUTO, 2020) ou ter familiares nessa condição ou até mesmo pelo próprio distanciamento social. Nessa ótica, fazemos o seguinte questionamento: Quais são os impactos da pandemia da COVID-19 para os professores da educação superior, no Brasil? O presente estudo envolveu 67 docentes de instituições de educação superior (IES) públicas e privadas, caracterizadas como universidades, centros universitários, faculdades e institutos federais do Brasil.

Desse modo, o objetivo geral foi identificar os impactos do distanciamento em professores da educação superior no Brasil em tempo de pandêmica da COVID19.

\footnotetext{
${ }^{1}$ A situação de pobreza é caracterizada pela renda domiciliar per capita inferior ao equivalente a US\$ 5,50 (IBGE, 2019).
}

Revista de Estudos e Pesquisas sobre Ensino Tecnológico, v. 6, Edição Especial Desafios e avanços educacionais em tempos da COVID-19, 140720, 2020. 


\section{Desenvolvimento}

A partir da análise dos dados publicados pelo Centro Chinês de Controle e Prevenção de Doenças, Wu e McGoogan (2020) encontraram uma taxa geral de mortalidade de $2,3 \%$ em uma amostra de 44.672 casos confirmados, o que corresponde a 1.023 óbitos. Nessa direção, Aquino et al. (2020) esclarece que embora a letalidade possa ser considerada baixa, a alta transmissibilidade resulta em um número absoluto de mortes mais elevado que o produzido pela combinação das epidemias causadas por outros coronavírus, especificamente, SARS-Cov e MERS-Cov. Porém, esse percentual aumenta na presença de comorbidades pré-existentes, como, doenças cardiovasculares $(10,5 \%)$, diabetes $(7,3 \%)$, doenças respiratórias crônicas $(6,3 \%)$, hipertensão $(6,0 \%)$ e câncer $(5,6 \%)$ (WU; MCGOOGAN, 2020).

Durante o desenvolvimento desta pesquisa, em maio de 2020, o Brasil foi considerado o "epicentro" em casos na América do Sul com mais de 500 mil infectados e 30 mil óbitos, no entanto, o Ministério da Saúde brasileiro registrou cerca de $50 \%$ de pessoas curadas da doença (BRASIL, 2020a). Vale mencionar que os esforços científicos têm sido realizados para encontrar meios de minimizar a enfermidade, como testes com vacinas e medicamentos, ainda sem respostas efetivas.

Diante do cenário, as restrições de aglomeração e circulação de pessoas são recomendações para combater a pandemia, e no Brasil, não tem sido diferente.

No tocante à Educação, em março de 2020 as instituições da Educação Básica à Superior paralisaram suas atividades presenciais e uma Nota Técnica Conjunta $\mathrm{n}^{\circ}$ 17, de junho de 2020, do Ministério da Educação dispõe sobre a substituição das aulas presenciais pelas remotas até 31 de dezembro de 2020 na Educação Superior (BRASIL, 2020b).

A Educação Superior no Brasil, objeto deste estudo, em 2018, contou com 2.537 IES públicas e privadas, sendo 107 e 92, respectivamente, na categoria universidade, 13 Centros Universitários públicos e 217 privados, 139 faculdades públicas e 1.929 privadas e 40 Institutos Federais de Ciência e Tecnologia (IF), somente públicos. De acordo com o censo, 8.451 .748 estudantes estavam matriculados na Educação Superior, em 2018. O número supera as matrículas de 2017, de 8.290.911; em sua maioria nas IES privadas. São ofertados 33 mil cursos de graduação no total e, ainda, quase $45 \%$ das vagas oferecidas são preenchidas nos processos seletivos para preenchimento em cursos presenciais, já nos cursos a distância o preenchimento é de apenas $21,1 \%$, de acordo com Instituto Nacional de Estudos e Pesquisas Educacionais Anísio Teixeira (INEP, 2018).

No ano de 2018, registraram-se 384.474 docentes em atuação nas IES brasileiras, sendo 173.868 no âmbito público e 210.606 no privado. O perfil dos docentes expressa que a maioria é do sexo masculino, idade média de 38 anos e com regime de trabalho em tempo integral. A escolaridade dos docentes nas IES pública é nível doutorado e nas IES particulares é de mestrado (INEP, 2018).

Assim, como têm ocorrido as ações das IES, no âmbito brasileiro, para ofertar ensino durante o distanciamento social?

De acordo com Gusso (2020), as IES particulares estão, quase em sua totalidade, em atividades remotas de ensino, enquanto as públicas, $89 \%$ encontram-se 
paralisadas, apenas em continuidade com atividades de extensão e pesquisa. $\mathrm{O}$ citado autor aponta aspectos que distinguem o Ensino a Distância e o Ensino Remoto Emergencial:

Quadro 1. Comparativo entre Ensino à Distância e Ensino Remoto Emergencial

\begin{tabular}{|l|l|}
\hline \multicolumn{1}{|c|}{ Ensino à distância (EAD) } & \multicolumn{1}{|c|}{ Ensino Remoto Emergencial (ERE) } \\
\hline -Não é somente quando o professor está & -Ensino presencial migra para o online; \\
distante; & -É improvisado e sem recursos; \\
-Deve haver recursos e materiais adequados & -Não há treinamento aos professores; \\
para as partes envolvidas; & -Objetiva resposta rápida; \\
-Condições para ensino e assegurar suporte & -Não tem qualidade; \\
para seu prosseguimento; & -Pode haver funcionalidade ao acaso; \\
-Resposta rápida não é EAD & -Após o ERE pode haver evasão de estudantes, \\
-Treinamento aos professores e também aos & pois não conseguem cumprir as exigências; \\
alunos para desenvolver aulas à distância; & -Pode aproximar-se da EAD se professores e \\
-EAD bem estruturado tem resultado eficaz. & estudantes tiverem treinamento; \\
\hline
\end{tabular}

Fonte: Elaborado pelas autoras, baseado em Gusso (2020).

A EAD, no Brasil, é regulamentada na Lei de Diretrizes e Bases da Educação Nacional (LDBEN), 9.394, de 1996, no seu artigo 80 em que pontua: "O Poder Público incentivará o desenvolvimento e a veiculação de programas de ensino a distância, em todos os níveis e modalidades de ensino, e de educação continuada". Em 2017, o Decreto 9.057, regulamenta o artigo 80 da LDBEN, estabelecendo que:

[...] considera-se educação à distância a modalidade educacional na qual a mediação didático-pedagógica nos processos de ensino e aprendizagem ocorra com a utilização de meios e tecnologias de informação e comunicação, com pessoal qualificado, com políticas de acesso, com acompanhamento e avaliação compatíveis, entre outros, e desenvolva atividades educativas por estudantes e profissionais da educação que estejam em lugares e tempos diversos (BRASIL, 2017, Artigo 1, s.p).

Também, o Artigo 2 assegura: "A educação básica e a educação superior poderão ser ofertadas na modalidade a distância nos termos deste Decreto, observadas as condições de acessibilidade que devem ser asseguradas nos espaços e meios utilizados" (BRASIL, 2017, s.p).

O cenário de crise instalada propiciou que o Conselho Nacional de Educação, no Parecer 5/2020, autorizasse as aulas remotas, como também a forma híbrida (remota e presencial) para as IES, sendo assim fica clara a emergência das ações.

Gusso (2020) reporta caminhos fáceis e difíceis para essas ações à distância. O caminho fácil é evidenciado na maior parte das instituições, sendo: "todos devem ter acesso"; "todos estão em condições para o acesso" e "ensinar é transmitir". Nesse sentido, o citado autor argumenta que há uma solução fácil para o problema e assevera o descompromisso com a qualidade do ensino e da aprendizagem. Já o que ele considera a solução difícil consiste em preparar os professores, pois há muitas dificuldades, ainda, com acesso a recursos didáticos e tecnológicos para a EAD, além da significante inacessibilidade dos estudantes em condições de vulnerabilidade, tais quais, os indígenas e os que vivem em situação de pobreza. 
Ainda, Menezes et al. (2020, s.p) pontuam que, aliado a tudo a isso a "diversidade da própria situação de isolamento das pessoas e das suas condições subjetivas e materiais exigem muito mais que tecnologias de "entrega" de conteúdos curriculares. A "aula remota" não pode ser confundida com as diversas possibilidades que envolvem a educação online".

Quanto aos recursos e infraestrutura das IES públicas federais, Gusso comenta os cortes que elas vêm passando devido à crise econômica e a falta de investimentos ${ }^{2}$ que prejudicam o estabelecimento para o desenvolvimento da EAD. Desse modo, ele recomenda aos gestores das IES para se apropriarem da situação que os docentes se encontram, pois eles podem estar em situação de risco para doença da COVID-19, ter uma pessoa próxima em risco, estarem passando por mudança drástica de rotina doméstica, entre outras condições, ainda, consultarem os docentes para que iniciativas sejam tomadas e realizadas conjuntamente para evitar a unilateralidade ou interferências externas à instituição.

Nessa mesma direção, Menezes et al. (2020) argumentam que as tecnologias oferecem muitas possibilidades para dar conta da distância física e têm oportunizado a docentes e estudantes reinventarem seus espaços de ensinagem e de aprendizagem. No entanto, acrescentam que o contexto de distanciamento tem exigido das pessoas e de suas famílias adaptarem-se a situações diversas e, muitas vezes, adversas, tais como o desemprego e/ou a redução dos vencimentos, o cuidado com os mais idosos e as crianças, a reunião de várias pessoas em casas com poucos cômodos, além de baixa qualidade ou falta de acesso à internet (MENEZES et al., s.p).

E acrescentam:

Por mais expertise e boa vontade que as instituições educacionais tenham, a EaD não é capaz de suplantar o distanciamento social brasileiro fruto da desigualdade de condições de vida, de habitação, de trabalho. Isso antecede à pandemia e está sendo desnudado por ela (Menezes et al., s.p).

Também, Witze (2020) acredita que mudanças ocorrerão pós-pandemia. Entre essas mudanças estão:

a) alguns pesquisadores acreditam que universidades criarão agências de fomento para realizar projetos de infraestrutura relevantes aos interesses póspandemia; b) valorização das IES para solução dos problemas decorrentes, desfocando de vieses elitizados que sempre estiveram presentes; e c) o autor duvida que haverá término ou diminuição das IES como ocorreu na pandemia da peste negra no século XIV.

\section{MÉTODO}

A presente pesquisa desenhou-se em nível descritivo e com delineamento de survey. Gil (2008) aponta que as pesquisas descritivas se destinam a descrever

\footnotetext{
2 Desde o congelamento do limite de investimentos em educação e saúde estabelecido pela Emenda Constitucional no 95/2016, agravado por recentes contingenciamentos e redução no orçamento do Ministério da Educação, as IES públicas têm passado por dificuldades na ampliação do acesso, manutenção e modernização de infraestrutura e, sobretudo, de financiamento à pesquisa. Para maiores informações, recomenda-se a leitura de Ximenes et al. (2020).
} 
características de determinada população ou fenômeno e ou estabelecimento de relações entre variáveis. Survey examina uma amostra da população, sendo que oferece um método de verificação empírica, pois envolve quantificação de dados e se torna fonte permanente de informação ao facilitar réplicas posteriores em outras amostras e subgrupos, por parte de outros pesquisadores (BABBIE, 1986). Segundo Gunther (1999), o instrumento adequado ao survey é o questionário, o qual é composto por um conjunto de perguntas que versam sobre um dado assunto e pode ser administrado na interação direta ou por autoaplicação.

A coleta de dados ocorreu no mês de maio de 2020 e teve a duração de duas semanas. $O$ instrumento usado foi um questionário com perguntas abertas e fechadas, elaborado no Google Forms, um aplicativo online que tem por finalidade a administração de pesquisas. O questionário foi encaminhado via email, WhatsApp ou redes sociais para professores de IES das cinco regiões do país, cujas autoras deste artigo possuíam contato. O convite para participar da pesquisa foi acompanhado da solicitação de divulgação do estudo entre pares, constituindo assim, uma amostra não probabilística que caracteriza como do tipo "bola de neve", de modo a formar cadeias de referência (ALBUQUERQUE, 2009).

$\mathrm{Na}$ página inicial do questionário, os professores eram esclarecidos sobre os objetivos, procedimentos, tempo médio de preenchimento, riscos, finalidades e caráter voluntário e anônimo da participação. Somente depois de manifestarem o consentimento livre e esclarecido, eram encaminhados às questões. Participaram 67 docentes de IES públicas e privadas do Brasil, os quais foram nomeados numericamente (1 a 67 ).

Os dados obtidos na aplicação dos questionários foram submetidos à análise lexical a partir do processamento do corpus textual no software Interface de $R$ pour les Analyses Multidimensionnelles de Textes et de Questionnaires (IRAMUTEQ). Cabe explicitar que o corpus foi composto por 67 questionários respondidos pelos participantes.

O software divide o corpus em segmentos de texto, os quais recebem o nome de Unidades de Contexto Elementar (UCE) e possuem extensão aproximada de 10 a 20 palavras. A análise lexicográfica efetuada promove um cruzamento entre as UCE (BARBIÉRI; FRANCO, 2018).

Entre outras funcionalidades, o IRAMUTEQ possibilita gerar uma nuvem de palavras com base na frequência com que aparecem, bem como realizar a Classificação Hierárquica Descendente (CHD), por meio da qual são criadas classes lexicais que derivam do compartilhamento de vocabulário específico, isto é, cada classe apresenta um vocabulário comum entre si, mas diversificado em relação aos que compõem as demais classes. Diferentemente da nuvem de palavras, que se baseia unicamente na quantificação, a CHD considera o contexto em que a palavra se apresenta, "tornando possível integrar níveis quantitativos e qualitativos na análise, trazendo maior objetividade e avanços às interpretações dos dados de textos" (CAMARGO; JUSTO, 2013, p. 517). Assim, não restringimos nossa análise à quantificação do vocabulário, mas retomamos o contexto das palavras mais representativas de cada classe para extrair o significado dos enunciados. A seguir, a Figura1 ilustra os caminhos da pesquisa. 
Figura 1. Representação dos caminhos da pesquisa

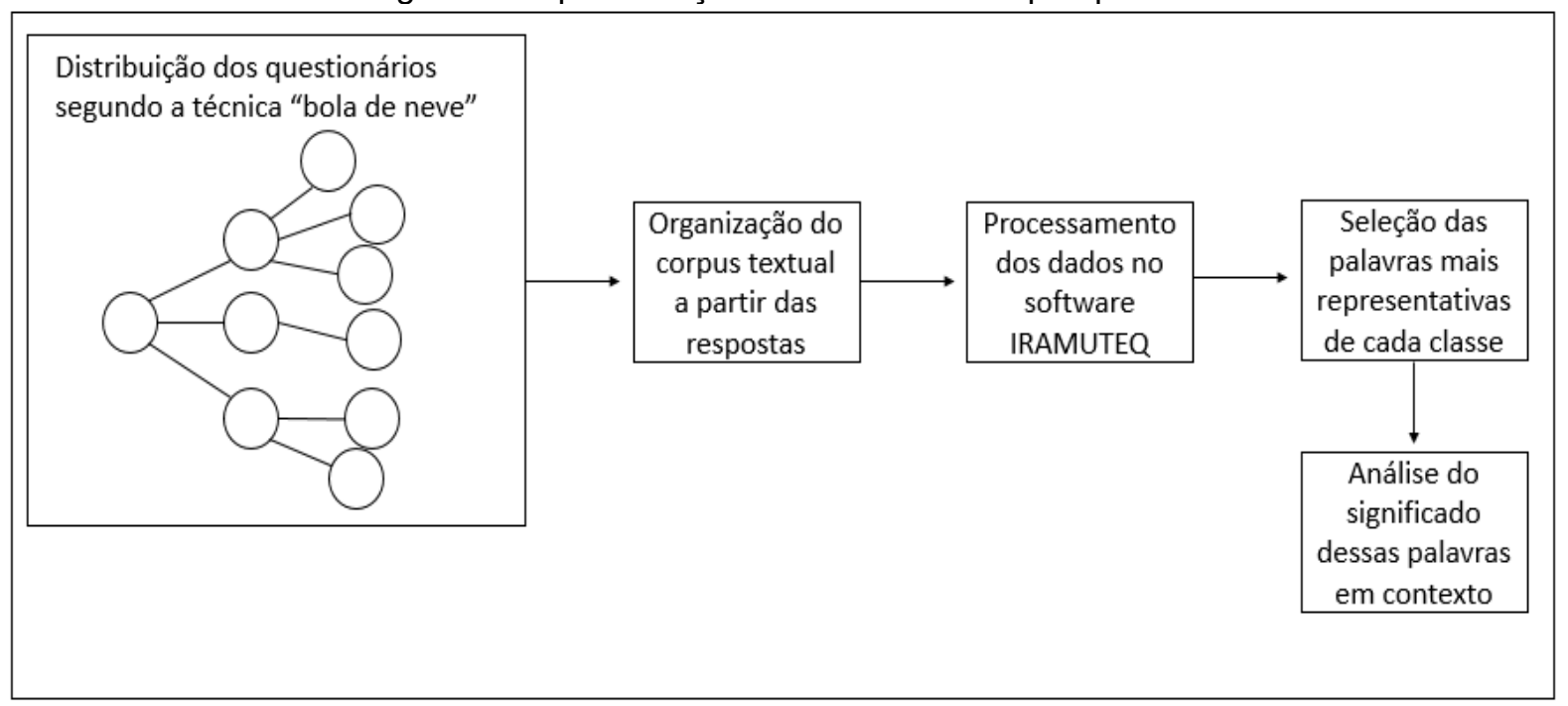

Fonte: Elaboração própria a partir do percurso metodológico.

\section{Resultados}

Caracterização dos participantes

Entre os 67 professores participantes da pesquisa, 47 eram do gênero feminino $(70,1 \%)$ e 20 , do gênero masculino $(29,9 \%)$. A distribuição da amostra segundo a faixa etária pode ser observada na Tabela 1 :

Tabela 1. Faixa etária dos participantes

\begin{tabular}{lcc}
\hline Faixa etária & $\mathrm{n}$ & $\%$ \\
\hline 25-34 anos & 10 & 14,9 \\
35-44 anos & 26 & 38,8 \\
$45-54$ anos & 19 & 28,4 \\
55-64 anos & 6 & 9,0 \\
65-74 anos & 5 & 7,4 \\
Não informado & 1 & 1,5 \\
\hline Total & 67 & 100,0 \\
\hline \multicolumn{2}{c}{ Fonte: } & Respostas dos participantes ao questionário.
\end{tabular}

Em relação à formação acadêmica, 16 dos participantes possuíam mais de uma graduação, sendo que os cursos referidos foram: Pedagogia (22), Educação Física (11), Administração (9), Letras (5), Direito (4), Ciências Contábeis (4), Ciências econômicas (3), Ciências Biológicas (3), Psicologia (3), Nutrição (2), Comunicação Social (2), Ciências da Computação (2), Ciências Sociais (1), Ciências Religiosas (1), Fonoaudiologia (1), Secretariado Executivo (1), Análise e Desenvolvimento de Sistemas (1), Processamento de Dados (1), Física (1), Estatística (1), Matemática (1), História (1), Geografia (1), Enfermagem (1), Terapia Ocupacional (1) e Música (1). A maioria dos professores tem o Doutorado como o nível mais elevado de formação $(38,56,7 \%)$, seguido do Mestrado (16, $23,9 \%)$. Três professores atuam no ensino superior como especialistas $(4,5 \%)$ e são dez os que possuem curso de Pós-Doutorado $(14,9 \%)$. A Tabela 2 exibe as áreas de pesquisa a que se dedicam: 
Tabela 2. Áreas de pesquisa dos participantes

\begin{tabular}{|c|c|c|c|c|}
\hline \multirow[t]{2}{*}{ Categoria } & \multirow[t]{2}{*}{ Componentes } & \multirow[t]{2}{*}{$\mathrm{n}$} & \multicolumn{2}{|c|}{ Total } \\
\hline & & & $\mathrm{n}$ & $\%$ \\
\hline Educação e Ensino & $\begin{array}{l}\text { Educação } \\
\text { Educação Especial } \\
\text { Educação Física/Motricidade } \\
\text { Ensino de Ciências }\end{array}$ & $\begin{array}{c}17 \\
9 \\
5 \\
1\end{array}$ & 32 & 47,7 \\
\hline $\begin{array}{lll}\text { Ciências } & \text { Sociais } & \text { e } \\
\text { Econômicas } & & \end{array}$ & $\begin{array}{l}\text { Ciências Sociais Aplicadas } \\
\text { Políticas Sociais } \\
\text { Economia/Economia aplicada } \\
\text { Comunicação Social } \\
\text { Administração }\end{array}$ & $\begin{array}{l}1 \\
1 \\
2 \\
3 \\
8\end{array}$ & 15 & 22,4 \\
\hline Ciências Exatas & $\begin{array}{l}\text { Matemática } \\
\text { Engenharia } \\
\text { Estatística } \\
\text { Física } \\
\end{array}$ & $\begin{array}{l}2 \\
1 \\
1 \\
1\end{array}$ & 5 & 7,5 \\
\hline Saúde e Biologia & $\begin{array}{l}\text { Genômica } \\
\text { Bioquímica } \\
\text { Enfermagem } \\
\text { Ciências Fisiológicas } \\
\text { Clínica Médica }\end{array}$ & $\begin{array}{l}1 \\
1 \\
1 \\
1 \\
1\end{array}$ & 5 & 7,5 \\
\hline Cultura, Espaço e Tempo & $\begin{array}{l}\text { História Cultural } \\
\text { Geografia Humana } \\
\text { Letras/Letras e Artes }\end{array}$ & $\begin{array}{l}1 \\
1 \\
2 \\
\end{array}$ & 4 & 6,0 \\
\hline Psicologia & $\begin{array}{l}\text { Psicologia } \\
\text { Psicologia Escolar } \\
\text { Desenvolvimento Humano }\end{array}$ & $\begin{array}{l}1 \\
1 \\
1\end{array}$ & 3 & 4,5 \\
\hline Tecnologia & $\begin{array}{l}\text { Tecnologia da Informação } \\
\text { Tecnologia e Sociedade }\end{array}$ & $\begin{array}{l}1 \\
1 \\
\end{array}$ & 2 & 2,9 \\
\hline$\frac{\text { Não informado }}{\text { Total }}$ & & 1 & $\frac{1}{67}$ & $\frac{1,5}{1000}$ \\
\hline
\end{tabular}

Fonte: Respostas dos participantes ao questionário.

Os participantes se vinculam a 30 IES no país, das quais 16 são públicas e 14 , privadas. As instituições públicas estão divididas em federais (9), estaduais (4) e municipais (3), constituindo-se como local de trabalho de 40 participantes $(61,5 \%)$. Destaca-se que dois professores não quiseram informar suas instituições de pertencimento. Todos lecionam em cursos de graduação e 25 estão credenciados em Programas de Pós-Graduação (37,3\%).

No que tange à distribuição geográfica, a Tabela 3 apresenta o número de professores em instituições públicas e privadas localizadas nas cinco regiões do país.

Tabela 3. Número de professores em instituições públicas e privadas

\begin{tabular}{lcccccc}
\hline & \multicolumn{2}{c}{ Públicas } & \multicolumn{2}{c}{ Privadas } & \multicolumn{2}{c}{ Total } \\
Região & $\mathrm{n}$ & $\%$ & $\mathrm{n}$ & $\%$ & $\mathrm{n}$ & $\%$ \\
\hline Norte & 2 & 5,0 & 0 & 0,0 & 2 & 3,1 \\
Nordeste & 9 & 22,5 & 1 & 4,0 & 10 & 15,4 \\
Centro-Oeste & 16 & 40,0 & 2 & 8,0 & 18 & 27,7 \\
Sudeste & 8 & 20,0 & 21 & 84,0 & 29 & 44,6 \\
Sul & 5 & 12,5 & 1 & 4,0 & 6 & 9,2 \\
\hline Total & 40 & 100,0 & 25 & 100,0 & 65 & 100,0 \\
\hline
\end{tabular}

Fonte: Respostas dos participantes ao questionário. 
O corpus composto, a partir de 67 questionários, apresentou 8791 ocorrências, contendo 2091 palavras diferentes e originando 579 unidades de contexto elementares. A Figura 2 representa a composição do vocabulário analisado conforme a ocorrência das palavras.

Figura 2. Nuvem de palavras

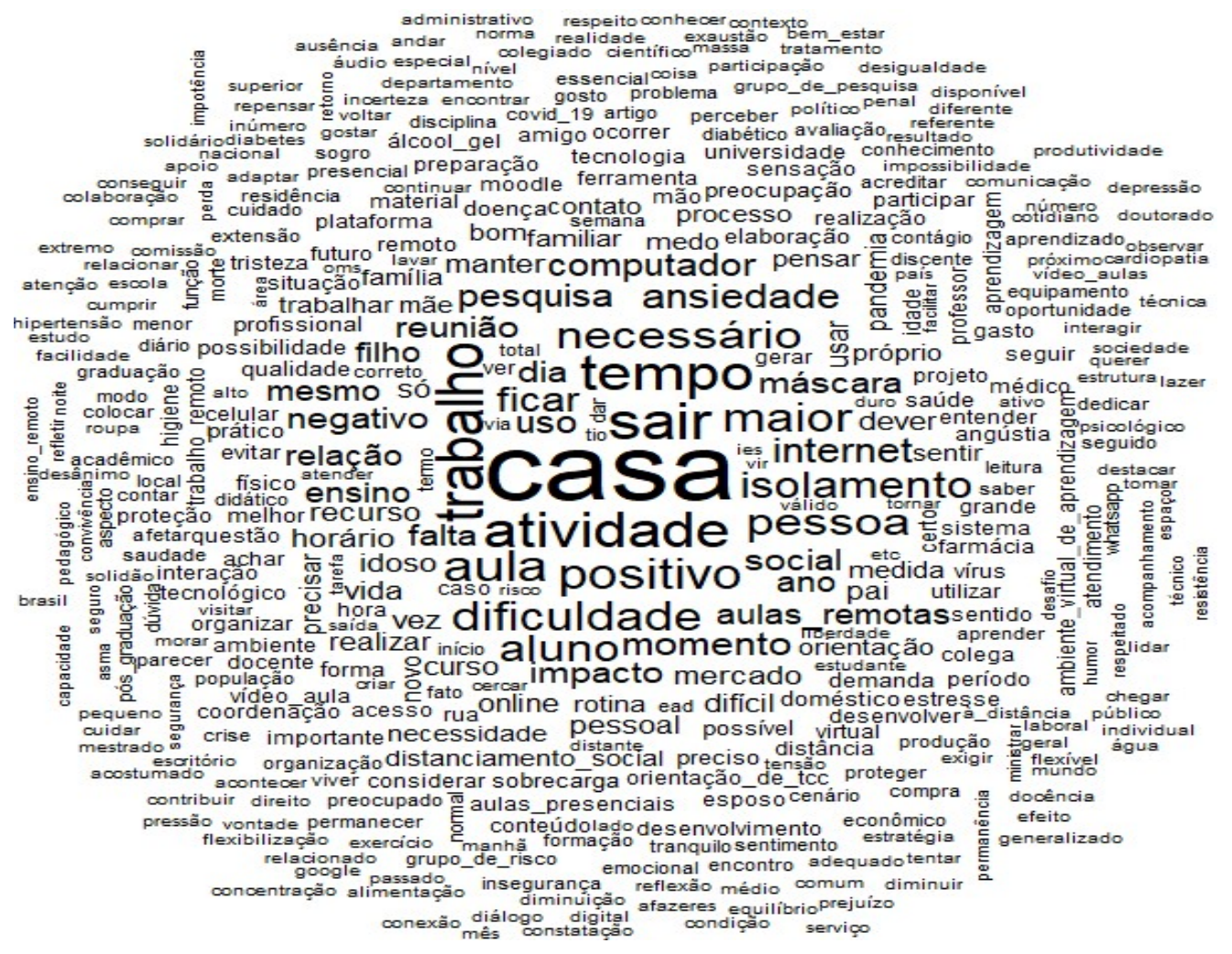

Fonte: Gerado pelo software IRAMUTEQ.

Como é possível observar, as 20 palavras mais referidas pelos professores foram: casa (114), sair (54), trabalho (54), atividade (53), tempo (53), aula (44), positivo (41), maior (39), dificuldade (38), necessário (36), pessoa (36), aluno (35), isolamento (35), ficar (31), internet (30), ansiedade (29), momento (28), computador (25), pesquisa (25) e uso (25). A Figura 3 apresenta a Classificação Hierárquica Descendente, com destaque para as palavras consideradas de maior representatividade, cujo aproveitamento do material textual foi de $85 \%$, o que indica "boa consistência interna e adequação do conteúdo submetido" (BARBIÉRI; FRANCO, 2018, p. 218). 
Figura 3. Classificação Hierárquica Descendente

\begin{tabular}{|c|c|c|c|c|c|c|c|}
\hline \multicolumn{2}{|c|}{$\begin{array}{l}\text { Classe } 1 \text { - Impactos da } \\
\text { Covid-19 (46,5\%) }\end{array}$} & \multicolumn{2}{|c|}{$\begin{array}{l}\text { Classe } 2 \text { - Distanciamento } \\
\text { social }(16,1 \%)\end{array}$} & \multicolumn{2}{|c|}{$\begin{array}{l}\text { Classe } 3 \text { - Medidas } \\
\text { adotadas }(24,3 \%)\end{array}$} & \multicolumn{2}{|c|}{$\begin{array}{l}\text { Classe } 4 \text { - Atividade } \\
\text { docente }(13,9 \%)\end{array}$} \\
\hline & $P$ & & $P$ & & $P$ & & $P$ \\
\hline Dificuldade & $<0,0001$ & Necessário & $<0,0001$ & Casa & $<0,0001$ & Aulas remotas & $<0,0001$ \\
\hline Ansiedade & $<0,0001$ & Importante & $<0,0001$ & Sair & $<0,0001$ & Pesquisa & $<0,0001$ \\
\hline Tempo & $<0,0001$ & Saúde & $<0,0001$ & Computador & $<0,0001$ & Reunião & $<0,0001$ \\
\hline Familiar & $<0,0001$ & Doença & $<0,0001$ & Máscara & $<0,0001$ & Orientação & $<0,0001$ \\
\hline Falta & $<0,0001$ & Proteger & $<0,0001$ & Mercado & $<0,0001$ & Elaboração & $<0,0001$ \\
\hline Medo & $<0,0001$ & Contágio & $<0,0001$ & Farmácia & $<0,0001$ & Moodle & $<0,0001$ \\
\hline Novo & 0,00012 & Covid-19 & 0,00071 & Celular & $<0,0001$ & Pós-graduação & $<0,0001$ \\
\hline Qualidade & 0,00092 & Grupo de risco & 0,00131 & Álcool em gel & $<0,0001$ & Vídeo-aulas & $<0,0001$ \\
\hline Ferramenta & 0,00092 & Vírus & 0,00297 & Mão & 0,00013 & Comissão & $<0,0001$ \\
\hline Angústia & 0,00181 & Evitar & 0,00326 & Lavar & 0,00039 & Artigo & 0,00017 \\
\hline Futuro & 0,00181 & Isolamento & 0,01604 & Cumprir & 0,00039 & WhatsApp & 0,00278 \\
\hline Estresse & 0,00704 & Adequado & 0,01705 & Higiene & 0,00343 & & \\
\hline Saudade & 0,00704 & Vida & 0,01813 & Distância & 0,01114 & & \\
\hline Aprender & 0,00704 & & & Cuidado & 0,01499 & & \\
\hline Sobrecarga & 0,00840 & & & & & & \\
\hline Dedicar & 0,01400 & & & & & & \\
\hline Seguro & 0,02814 & & & & & & \\
\hline
\end{tabular}

Fonte: Elaborado a partir do processamento de dados no software IRAMUTEQ.

Inicialmente, o corpus dividiu-se em dois subcorpus: do lado direito tem-se a Classe 4 e do lado esquerdo, as demais. Em seguida, a Classe 3 foi isolada, de maneira que o eixo que une as Classes 1 e 2 evidencia a proximidade existente entre elas. A classe com o maior número de UCE e consequentemente, de maior representatividade do corpus, é a Classe 1, com 46,5\% das UCE classificadas. Apresentaremos exemplos da composição das classes seguindo a ordem crescente de representatividade.

A Classe 4, com 13,9\% das UCE, foi denominada "Atividade docente" porque engloba as UCE relacionadas às ações e aos recursos que os professores estão envolvendo em suas atividades laborais no período de distanciamento social. São exemplos de frases características dessa classe:

Participação em reuniões de órgãos colegiados, parecer em artigos científicos e projetos de iniciação científica, correção de trabalhos de pesquisa a nível de mestrado e iniciação científica, parecer em relatório docente e encontros virtuais com grupo de pesquisa". (Professora $\mathrm{n}^{\circ} 49$ )

"[Tenho trabalhado] da minha casa, com recursos próprios, por meio de aulas remotas (online)" (Professora $\mathrm{n}^{\circ} 18$ ).

Ressalta-se que a maioria dos professores participantes da pesquisa $(37 ; 55,2 \%)$ afirmou ter havido a suspensão do calendário acadêmico em decorrência da COVID-19 nas IES em que atuam. Em contrapartida, 30 docentes (44,8\%) estavam desenvolvendo todas as suas atividades ordinárias remotamente. Ademais, esclarece-se que a suspensão do calendário implica a ausência de aulas na graduação, mas não interrompe as atividades administrativas, de 
extensão, de pesquisa, tampouco interfere no calendário da Pós-Graduação Stricto Sensu (Mestrado e Doutorado).

A Classe 2 engloba excertos que revelam opiniões dos professores sobre as medidas de distanciamento social. A seguir, são apresentados alguns exemplos:

Como professor é evidente o prejuízo causado aos alunos, que terão sua formação atrasada. No entanto, entendo que esse isolamento se faz necessário neste momento para que seja evitado o maior prejuízo, que é o risco à vida em caso de um retorno nesse momento" (Professor $\left.n^{\circ} 30\right)$.

A [universidade] adotou no momento certo o isolamento social (desde 07/03) e vem prolongando este período conforme o avanço da pandemia. Mas o município [...] não segue este isolamento. As lojas de rua, salões de beleza e shoppings estão abertos. Essas medidas causam insegurança e confusão na população. Temo que todo esforço de isolamento seja perdido com a saída da população para as ruas (Professora $n^{\circ}$ 63).

"Creio que deveríamos ter equilíbrio. Rodízio de trabalho com segurança e isolamento do grupo de risco. Pois, há possibilidade de as pessoas morrerem de fome, depressão e solidão, se protegendo do COVID-19" (Professora $n^{\circ} 55$ ).

"O negativo é a privação de atividades que estava acostumado, agora o positivo é a preservação da saúde da minha família e contribuição para evitar a propagação da COVID-19 em nossa cidade" (Professor $n^{\circ} 30$ ).

A Classe 3 reúne $24,3 \%$ das UCE e abrange as atitudes que os professores estão tomando para a prevenção do risco de contágio por COVID-19 e por isso, foi denominada "Medidas adotadas". Seguem alguns exemplos:

"É trabalhoso... nos protege e simultaneamente nos distancia. Ao cruzar com pessoas, mesmo de máscara, tomo distância maior. É como se fosse um estranhamento coletivo" (Professora n² 42).

"Não saio de casa e, se precisar sair, utilizo máscaras mantenho distância e uso álcool gel" (Professora n 65).

A Classe 1, a mais extensa do corpus (46,5\% de UCE), foi composta pelos trechos que se relacionam aos impactos da COVID-19 para os professores da educação superior, alguns considerados positivos e outros, negativos, como mostram os seguintes exemplos:

"[...] estar relativamente seguro em relação ao vírus" (Professora $n^{\circ} 23$ ).

"[...] aprender a usar mais ferramentas online". (Professora $\mathrm{n}^{\circ} 1$ ).

"[...] poder ficar mais em casa e curtir minha família" (Professora $n^{\circ} 6$ ).

"Difíceis no que diz respeito ao ambiente de trabalho, pois tenho um filho de 5 anos que a todo tempo precisa de atenção, e, além disso, preciso conciliar essas atividades com as tarefas domésticas" (Professora $n^{\circ} 67$ ).

"Ansiedade e preocupação devido à necessidade de me manter seguro e aos meus familiares no atual cenário de pandemia" (Professor $n^{\circ} 20$ ).

[...] O medo ao redor tende a nos afetar e isso gera tensão, isso é ruim. Há uma preocupação financeira também: preços subindo, ameaças de decretos presidenciais e a própria dificuldade de outras pessoas ajudadas por iniciativas solidárias das quais participo gera ansiedade 
sobre a capacidade de prover por minha família em um futuro bem próximo (Professora $\mathrm{n}^{\circ} 6$ ).

[...] Muitas dificuldades. Acúmulo de trabalho por falta de planejamento para estudos dirigidos e trabalho remoto junto aos alunos. Alunos sem qualquer possibilidade material de acessar as atividades e interagir comigo, apesar de um grande número conseguir. Mesmo esses que conseguem, a qualidade da interação não é boa, o que impacta na qualidade da formação (Professor $n^{\circ} 47$ ).

"Negativo: Gostaria que todos os estudantes tivessem acesso com equidade" (Professora $\mathrm{n}^{\circ}$ 1).

"Maior sobrecarga de trabalho, sensação de sobrecarga, de solidão, de impotência e dificuldades em manter uma vida social ativa" (Professora $n^{\circ} 18$ ).

Destaca-se que as professoras $n^{\circ} 1$ e $n^{\circ} 6$ apontaram tanto impactos negativos quanto positivos, conforme mostrado nos exemplos anteriores. Tal ponderação não foi exceção entre os participantes.

\section{Discussão e considerações finais}

Os resultados nos mostram que a COVID-19 ocasionou diversos impactos aos professores de nossa amostra. Alguns impactos são de ordem emocional, outros, referentes à mudança imposta à dinâmica de trabalho, havendo ainda, aqueles mais voltados à sociabilidade.

Quanto ao aspecto emocional, as respostas dos participantes são compatíveis à Menezes et al. (2020) ao afirmarem que os professores tendem a receberem os impactos em decorrência das medidas de distanciamento de seus entes próximos como ao mudar completamente a rotina social, solidão e mudanças impostas à dinâmica de trabalho, o que evidencia uma sobrecarga de tarefas. A esse respeito, muitas IES não estavam preparadas para aulas remotas (GUSSO, 2020), oferecendo-as de forma emergencial, causando preocupações e estresse aos professores em relação à organização para um novo formato de aulas e sua qualidade, conforme as declarações de professores.

As privações da vida social e de mudanças na rotina de trabalho refletem o sofrimento psíquico que pode estar ocorrendo entre os professores das IES, tendo em vista as respostas obtidas. Os efeitos da pandemia ainda são incertos em futuro próximo, mas muitos acreditam que as IES não serão mais as mesmas, a partir das mudanças impostas pelo contexto pandêmico, pois as aulas e eventos acadêmicos remotos serão práticas comuns na rotina pós COVID-19 (WITZE, 2020).

Nessa perspectiva, entendemos que os respondentes estiveram "administrando" situações durante o quadro da crise, tais quais: distanciamento obrigatório versus consequências emocionais, por exemplo, o que possivelmente pode causar danos a esses profissionais em sentirem-se impotentes e sozinhos e muitas vezes fazem parte do quadro de risco (SOUTO, 2020). Então, o que as IES têm feito para apoiá-los ou irão fazer? Quais as medidas governamentais, em termos de recursos e políticas, voltadas a dar suporte aos profissionais da educação superior? Que consequências emocionais mais graves os docentes podem ter, 
além das relatadas? Ficou evidente em algumas respostas que eles trabalham com recursos próprios, preocupados e se sentem sobrecarregados.

Mesmo diante de tantos desafios, muitos professores procuram enxergar positivamente a situação ao salientar a possibilidade de conhecer outras ferramentas e aprender novas tecnologias, bem como de sentir maior segurança em relação à saúde e estar mais tempo no lar, em companhia da família, ainda que o relato positivo esteja, na maioria das vezes, acompanhado pela percepção de consequências negativas já expostas anteriormente. Sob esse prisma, GarciaRey (2020) alerta para o crescimento da angústia e da frustração na medida em que se percebe a ausência de uma previsão de "normalidade" a curto prazo e, nesse sentido, salienta que o planeta está em fase de transformação, de maneira que impossibilita continuar fazendo as mesmas coisas, do jeito que se fazia até então, sendo imprescindível que nos reinventemos. Para isso, é necessário trabalhar coletivamente e buscar soluções capazes de minimizar os efeitos desencadeados pela grave crise sanitária.

Apesar dos impactos negativos, os professores reconhecem a importância do distanciamento social que estão enfrentando e adotam as medidas recomendadas: máxima permanência possível em casa, uso de máscara, álcool em gel, correta higiene das mãos e das roupas, distância mínima de 1,5m de outras pessoas. Essas são medidas que talvez permaneçam na cultura da população em geral.

As mudanças impostas pela COVID-19 fizeram com que os professores da educação superior tivessem que reinventar suas práticas sem qualquer preparo prévio e, muitas vezes, sem os meios necessários para isso, visto que a atividade laboral passou a ser desenvolvida no ambiente familiar, no qual nem sempre há espaço e mobiliário adequados em termos de ergonomia e acústica, internet com velocidade e estabilidade compatíveis com reuniões e/ou aulas virtuais, além da necessária compreensão por parte dos demais membros da família, visto que precisam respeitar o horário de trabalho desses professores, sem lhes solicitar atenção ou atribuir outras demandas.

Além dos entraves diretamente relacionados ao trabalho, existe a preocupação com a saúde e o estresse ocasionado pela privação do convívio social. Percebese que parte dos professores busca encontrar aspectos positivos em meio às adversidades, de modo a valorizar a oportunidade de zelar pela saúde própria e coletiva, aprender sobre o uso de novas tecnologias e passar mais tempo na presença dos familiares, entre outros, o que denota resiliência. Contudo, não é possível ignorar os efeitos psicológicos da pandemia: ansiedade, medo, angústia e estresse certamente interferem no desempenho profissional e na saúde dos professores da educação superior, sendo imprescindível que as IES, por meio de parcerias multiprofissionais e sociedade civil, desenvolvam ações no sentido de prestar apoio e suporte aos docentes. Obviamente, o apoio necessário aos professores, tanto em termos laborais práticos quanto de saúde física e psicológica, pode exigir a aplicação de recursos orçamentários, o que, no caso das instituições públicas, envolve questões governamentais relacionadas ao financiamento educacional, bem como a elaboração de políticas públicas voltadas para o fortalecimento da educação superior pública, gratuita e de qualidade. 


\section{Referências}

ALBUQUERQUE, Elisabeth Maciel. Avaliação da técnica de amostragem "Respondent-drivenSampling" na estimação de prevalências de Doenças Transmissíveis em populações organizadas em redes complexas. 2009. Dissertação (Mestrado em Ciências na área de Saúde Pública) - Escola Nacional de Saúde Pública Sérgio Arouca - ENSP; Rio de Janeiro: Ministério da Saúde Fiocruz, 2009. Disponível em: https://pesquisa.bvsalud.org/portal/resource/pt/lil535859. Acesso em: 14 maio 2020.

AQUINO, Estela, M. L. et al.. Medidas de distanciamento social no controle da pandemia de COVID-19: Potenciais impactos e desafios no Brasil. Ciência \& Saúde Coletivo [periódico na internet], v. 25, abr./2020. Disponível em: http://www.cienciaesaudecoletiva.com.br/artigos/medidas-de-distanciamentosocial-no-controle-da-pandemia-de-covid19-potenciais-impactos-e-desafios-nobrasil/17550?id=17550\&id=17550. Acesso em: 20 jun. 2020.

BABBIE, Earl. Métodos de Pesquisa de Survey. In: BABBIE, Earl. Observing Ourselves: Essays in Social Research. Belmont, CA: Wadsworth, 1986, [8] p.

BARBIÉRI, Elaine Silva Ferreti; FRANCO, Maria Laura Puglisi Barbosa. Profissão docente: uma revisão. Revista Educação e Emancipação, v. 11, n. 1, p. 214-231, 2018. Disponível em: http://dx.doi.org/10.18764/2358-4319.v11n1p214-231. Acesso em: 02 jun. 2020.

BOLETIM EPIDEMIOLÓGICO. Doença pelo coronavírus, 2019. Disponível em: https://portalarquivos.saude.gov.br/images/pdf/2020/April/09/be-covid-08-final2.pdf. Acesso em: 21 maio 2020.

BRASIL. Lei de Diretrizes e Bases da Educação Nacional $n^{\circ}$ 9.394. Presidência da República. Casa Civil. Subchefia para Assuntos Jurídicos, 1996. Disponível em: http://portal.mec.gov.br/seesp/arquivos/pdf/lei9394_Idbn1.pdf. Acesso em: 21 maio 2020.

BRASIL. Ministério da Saúde. Resposta nacional e internacional de enfrentamento ao novo coronavírus, 2020a. Disponível em: https://coronavirus.saude.gov.br/resposta-brasileira-a-emergencia. Acesso em: 18 jun. 2020.

BRASIL. Ministério da Educação. Nota Técnica $\mathbf{n}^{0}$ 17, junho de 2020b. Disponível em: https://www.semesp.org.br/wp-content/uploads/2020/06/SEI_MEC-2099369Nota-Te\%CC\%81cnica-Conjunta-17.pdf.pdf. Acesso em: 18 jun. 2020.

CAMARGO, Brígido Viseu; JUSTO, Ana Maria. IRAMUTEQ: Um software gratuito para análise de dados textuais. Temas em Psicologia, v. 21, n. 2, p. 513-518, 2013.Disponível em: http://dx.doi.org/10.9788/TP2013.2-16. Acesso em: 04 abr. 2020.

DÍAZ-CASTRILLÓN, F. J., TORO-MONTOYA, A. I. SARS-CoV-2/COVID-19: el virus, la enfermedad y la pandemia. Medicina \& Laboratorio, v. 24, n. 3, p. 183205, 2020. Disponível em: https://doi.org/10.36384/01232576.268. Acesso em: 07 jun. 2020.

GIL, Antonio Carlos. Métodos e técnicas de pesquisa social. São Paulo: Atlas, 2008. 
INSTITUTO BRASILEIRO DE GEOGRAFIA E ESTATÍSTICA [IBGE]. Síntese de Indicadores Sociais: uma análise das condições de vida da população brasileira. Rio de Janeiro: IBGE, 2019. Disponível em: https://biblioteca.ibge.gov.br/visualizacao/livros/liv101678.pdf Acesso em: 20 jul. 2020.

INSTITUTO NACIONAL DE ESTUDOS E PESQUISAS ANÍSIO TEIXEIRA [INEP]. Censo da Educação Superior 2018.Disponível em: http://download.inep.gov.br/educacao_superior/censo_superior/documentos/2019/ censo_da_educacao_superior_2018-notas_estatisticas.pdf. Acesso em: 15 jun. 2020.

MENEZES, Crediné; LOPES, Daniel; ZIEDE, Mariangela; ARAGÓN, Rosane. Educação à distância no contexto universitário, 2020. Disponível em: https://www.ufrgs.br/coronavirus/base/artigo-educacao-a-distancia-no-contextouniversitario/. Acesso em: 15 jun. 2020.

GARCIA-REY, Tariana. Cómo reinventarnos en la nueva era del COVID-19. Acta de Otorrinolaringología \& Cirugía de Cabeza Y Cuello, v. 48, n. 1, 2020. Disponível em: https://doi.org/10.37076/acorl.v48i1.509. Acesso em: 06 jul. 2020.

GUNTHER, Hartmut. Como elaborar um questionário. In: PASQUALI, Luiz. Instrumentos psicológicos: manual prático de elaboração. Brasília, DF: UnB, LabPAM/IBAPP, 1999.

GUSSO, Helder. Ensino superior durante a pandemia, 2020. Disponível em: https://www.youtube.com/watch?v=LZr7y8RnmB4\&fbclid=IwAR3KSLBdGB9zTuHc ilQpcW0OyXGoXRzRCMHDKKTdOvwFBhOlbrZUzZ4PH-o. Acesso em: 30 ago. 2020.

SOUTO, Geraldo Alves. Condições atuais da Covid-19, 2020. Disponível em: https://www.facebook.com/cechufscar/. Acesso em: 29 ago. 2020.

SUPREMO TRIBUNAL FEDERAL. Ministro assegura que estados, DF e municípios podem adotar medidas contra a pandemia. Notícias STF, Brasília, 08 abr. $2020 . \quad$ Disponível em: https://portal.stf.jus.br/noticias/verNoticiaDetalhe. asp?idConteudo=441075\&ori=1.

Acesso em: 18 nov. 2020.

WITZE, A. The universities will never be the same after the coronavirus crises. Nature, 2020.Disponível em: https://www.nature.com/articles/d41586-02001518-y. Acesso em: 30 jul.2020.

WU, Zunyou; MCGOOGAN, Jennifer. M. Characteristics of and important lessons from the coronavirus disease 2019 (COVID-19) outbreak in China: Summary of a report of 72314 cases from the Chinese Center for Disease Control and Prevention. JAMA, v. 323, n. 13, p. 1239-1242, 2020. Disponível em: https://doi.org/10.1001/jama.2020.2648. Acesso em: 05 ago. 2020.

XIMENES, Salomão Barros et al. Reafirmar a defesa do sistema de ciência, tecnologia e ensino superior público brasileiro. Educação \& Sociedade, v. 40, p. 1-4, 2019. Disponível em: http://dx.doi.org/10.1590/es0101-73302019230375. Acesso em: 18 nov. 2020. 
Recebido: $24 / 08 / 2020$

Aprovado: $17 / 11 / 2020$

Como citar: RANGNI, R. A.; MARTINS, B. A. A COVID-19 sob a ótica de professores da educação superior no Brasil. Revista de Estudos e Pesquisas sobre Ensino Tecnológico (EDUCITEC), v. 6, Ed. Esp. Desafios e avanços educacionais em tempos da COVID-19, e140720,2020.

Direito autoral: Este artigo está licenciado sob os termos da Licença Creative CommonsAtribuição 4.0 Internacional.

(c) (i) 